\title{
What is in a Name? A Social Semiotic Analysis of Papiackum Proverbial Names
}

\author{
Moustapha Reike Fandi* \\ Department of African Languages and Linguistics the University of Yaoundé I, Cameroon
}

DOI: $10.36348 /$ sijll.2020.v03i11.002

| Received: 10.09.2020 | Accepted: 18.09.2020 | Published: 30.11 .2020

*Corresponding author: Moustapha Reike Fandi

\section{Abstract}

Names are an important aspect in African culture given that the African does not name his or her children for naming sake. In most cases, names are given based on certain historical events or facts which can be peculiar to an individual, a family or the community as a whole. This is the case with the Papiackum community, a speech community situated in the Ngoketunjia Division, North West region of the Republic of Cameroon. This paper aims at analysing some of the proverbial names of this community to show that they are speech acts grounded on individual, family or collective history. From the theoretical paradigm of Social Semiotics, this study is based on the prism that Papiackum proverbial names are semiotic resources whose meanings are linked to their historical context. In this light, these names help to safeguard the history of the people for posterity while fostering social progress.

Keywords: Papiakum, Social semiotics, Semiotic resources, Historical context, Historical renditions.

Copyright () 2020 The Author(s): This is an open-access article distributed under the terms of the Creative Commons Attribution 4.0 International License (CC BY-NC 4.0) which permits unrestricted use, distribution, and reproduction in any medium for non-commercial use provided the original author and source are credited.

\section{INTRODUCTION}

Symbolic interactionists hold the view that human beings live in a world or environment of objects and their activities are formed around such objects. In other words, these objects are human constructs and not self- existing entities with intrinsic natures. This means that human group life entails interpreting these objects in the process of social interaction and designing a course of action. It is due to the fact that objects incarnate ideologies in human societies that Blumer [1] affirms that, to identify and understand the life of a group, it is primordial to identify its world of objects in terms of the meanings they have for the members of the group. The objects when interpreted can provide a glimpse of the philosophy of life of the society in question. It is based on this consideration that Blumer further ascertains the view that, human beings posses a self that indulges in introspections to interpret actions and objects at the non symbolic level rather than just reacting to stimulus.

Naming as an important aspect of group life has attracted debates whether or not they should be considered as objects or actions within a community. It is in line with these arguments that William Shakespeare once posed the question thus "what is in a name?" In other words, Shakespeare was in support of the school of thought which asserts that the significance of names does not go beyond the words of a page. However, this view has been debunked in African culture where names as objects speak volumes. It is due to the significance Africans attach to names that in a typical African society, there is always a ceremony in naming an individual. This shows that names in Africa are not just mere decorations but they carry a whole message behind them which can be spiritual, metaphysical, historical social or cultural.

To corroborate this view, Nwoye [2] through an ethnographic study of a naming ceremony in the Igbo community, affirms that the said ceremony is one of the Igbo birth rites and comes after the seclusion and purification rites. He also opines that, it is a peace offering ceremony in which the community comes together to pray for the child and the health of the parents. Similarly, Mphande [3] sheds light on the significance of names especially African names where he underscores that, African Americans in the New World maintained their African names when interacting with one another as a manifestation of their nostalgia for Africa, a symbol of their cultural identity despite the English surnames that are imposed on them by their slave masters. This phenomenon of naming is not only circumscribed to the Igbo community or to the African American society, but can be seen as a symbolic representation of Africa in general and the Papiackum community in particular where names are ideological 
,philosophical and moral when interpreted at the symbolic level.

This study aims at examining the historical contexts of Papiackum proverbial names in order to delineate their meanings or role in social interaction amongst members of the said community. Put differently, it will highlight the past events surrounding the names and their functions in the present and the future on the bearer of the name or society as a whole. This study is therefore predicated on the hypothetical consideration that, some Papiackum proverbial names are speech acts grounded on individual, family or collective past to put forth ideologies and philosophies of life that should or ought to have reflected community life in the past, the present and the future.

\section{Definition of Key Concepts}

For the purpose of conceptual clarity, this section sheds light on the key concepts under scrutiny which are names and historical renditions or the past. The past which is mostly referred to as memory has received much scholarly studies from different perspectives. To begin with, Brewer [4] focuses on what he terms "recollective memory" where he affirms that it is memory that occurs when an individual recalls a specific episode from his past experience. He further opines that in order to understand the nature and characteristics of the said memory, there is need to revisit the three fairly independent scholarly traditions that have contributed to it which range from philosophical, psychological studies of autobiographical memory to psychological studies of memory in the laboratory.

Philosophically, he commences by making reference to the types of memory and reevaluating their importance. In this guise, he affirms that traditional philosophy or the British empiricist's memory was equated with collective memory. He proceeds by quoting Bergson [5] and Russell [6] who distinguish between recollective and habit memory that is, memory for skilled action but emphasize that both scholars continued the traditional emphasis on recollective memory as the crucial form of memory reflected in the names they attach to it such as memory par excellence and true memory. He further quotes Bread [4] who presents three forms of memory namely, recollective, skill and propositional memory. He posits that the said author noted that memory of proposition cannot be identified with a mere power to repeat the sentences in which the propositions were expressed. This means that the utterances should be considered as indirect speech acts with implicit propositions. To show that there has been much reevaluation of, he quotes Malcolm [7] who notes that one can have a propositional memory of something without a recollective memory and also affirm that events are a blend of recollective and propositional memory. From these studies, he concludes that there has been much focus on recollective memory to the exclusion of other forms of memory; propositional memory was recognized as the most important form of memory or as the core for all other forms of memory.

As regards psychological studies of memory, he projects the view that one important issue in the study of recollective memory is the concern whether flashbulb memoires are to be considered as a form of recollective memory or as a separate form of memory. In this light, he describes flashbulb memories as memories for the circumstances of learning about a surprising and consequential event such as the assassination of John F. Kennedy. This means that these are memories related to very shocking historic events. In relation to the works of researchers where he quotes Brewer [4], Rubin and Kozin [8], he notes that the said memories showed few qualitative differences from ordinary recollective memory that portrays a reduced rate of forgetting.

In relation to psychological studies of memory in the laboratory, he alludes to Ebbighaus (1885/1964) which initiated laboratory studies of memory and raised theoretical issues about the nature of human memory that are yet to be resolved.As such, he recognizes two basic forms of memory namely, recollection and skill/implicit memory. He describes recollective memory as the form of memory in which we "can call back into consciousness by an exertion of the will directed to this purpose the seemingly lost states (or indeed, in case these consisted in immediate sense perceptions, we can recall their true memory images" (p.34). As for skill/implicit memory, he affirms that the "vanished mental states give indubitable proof of their continuing existence even if they themselves do not return to consciousness at all". Ebbinghaus did not see how it was possible to bring recollective memory under strict laboratory control and so invented the method of savings that is the improvement in the speed of learning a task that results from previous trials to study implicit memory. However, after his initial work, the researchers in the Ebbinghaus empire found the saving method too restrictive and began using various types of recall tasks. This decision therefore opens the way for recollective memoryto occur and give rise to conceptual and empirical problems that are visible.

As regards the empirical studies that accompanied Ebbinghaus' ideas, he alludes to Smith and McDougal who carried out an experiment designed to provide empirical support for recollective and skill memory. They formulated their experiment as a test of the distinction between true memory and habit memory. As such, they described one of the forms of memory as "recollections which in their very nature are unique experiences and the other as the power of forming mechanical associations." As a way of collecting data, they gave subjects two tasks that they thought were examples of recollective memory, namely, picture 
recall after a single exposure and form recognition after a single exposure. In addition, they gave the subjects two tasks that they thought were examples of skills memory notably CVC learning with multiple trials and a motor skill task with multiple trials. They found that the two recollective memory tasks were highly correlated and the two skills tasks were highly correlated and yet the recollective memory tasks were not correlated with the skill tasks. They also gave subjects a prose memory task and found that it was moderately correlated with both the recollective tasks and the skill tasks and so they suggested that this type of task involved both types of memory.

In line with this study and as mentioned above, name is a concept that necessitates scrutiny. In this regard, Anderson [9] presents some approaches to the study of names ranging from onomastics, philosophy of names to the linguistics of names. In terms of onomastics, he alludes to traditional onomastics which in the nineteenth century was largely concerned with the sources of names in the Indo-European Languages and the common structural principles that they appeared to share. Structurally, he posits that, by the last quarter of the nineteenth century, studies of Indo-European namesrecognized a division among names into compounded or dithematic names which compose of two elements each and are in principle associated with a common word and uncompounded or monothematic names, shortened forms of dithematic where some are interpreted as names or as names based on other names such as tall names originating in child speech or imitations thereof. Besides, he opines that, this study has revealed other aspects of names and naming namely, the distinctive phonological histories that names can be compared with the cognate non-name and the fact that they have a particular function and should be structured differently from non-names.

In addition, he expatiates on some schools of thought whom he believes are the starting point for the philosophical tradition of concern with names and the grammatical identification of names and nouns. These thoughts include Parmenides 'association of a name with the existence of a referent, Plato and Aristotle's concern with names as referring to particulars rather than universals denoted by lexical classes. He alludes to Mill as a key contributor to this debate who offers a cross-cutting classification of names that invokes six parameters which are proper names sub classified into general versus singular, concrete versus abstract and connotative versus non-connotative. He describes a concrete name as a name that stands for a thing, an abstract name as a name which stands for an attribute of a thing, a connotative name as one that denotes a subject and implies an attribute and a non-connotative name which signifies a subject only or an attribute only. It is as a result of these classifications that he refers to Mill's idea as the "modified Millian position because of his not accepting that names are totally without sense or connotation thus concluding that they do not denote types but display a limited set of distinction in sense associated with the types of which they are tokens.

As regards studies on the linguistics of names, he represents names as nouns. To substantiate this idea, he alludes to the idea of the stoics that names belong to a different word class from nouns and Anderson [9] who associates names with determinatives that is pronouns and determiners. He further notes that despite the disparity in the distribution of names and noun in many works, the status of names as a sub class of noun is apparently unquestioned. As for names based on names, he asserts that availability of street, road and avenue ensures the coining of a series of names based on the same personal or other names thus correlating with the view that street names as well as buildings are usually name-based names. This section has provided various ideas on the past and names but in line with this study, the past represents any events whether personal or collective that took place before naming while names are proverbial names peculiar to the Papiackum community.

\section{LITERATURE REVIEW}

There exist a number of scientific publications on names and the discourse surrounding it as scholars have analyzed it from different perspectives and cultural settings. In as much as these wide range of opinions serve as a background to this study, they equally shed light as well as isolate it. To begin with, Ogunwale [10] examines Yoruba personal names from the prism of pragma-linguistics. This study which dwells on the vocative function of names, found that only pity expressions could be appropriate. It also notes that proverbial expressions are copious yet a group of them are sometimes used as names. It further reveal that Yoruba proverbial names are part of genres that ensure continuity of identity and consistency of ethos in preliterate Yoruba society given that the interpretations that names suggest contain truth-value that cannot be faulted. This study like the present one focus on the cultural relevance of names. They are different in that the present study examines the role of names in fostering social progress.

Nwoye [2] examines the Igbo naming ceremony through an ethnographic study. This study seemed to provide answers to a number of questions in relation to this ceremony namely, what is the ceremony concerned with? What according to the Igbo must a name be given a child? What are the myths regarding the consequences of omitting it in a child's life? What processes and procedures are followed in this practice? What ritual objects are implicated? What kinds of prayers are used in the process and what are the indigenous Igbo religious interpretations of its meaning and significance in the life of the child? This study reveal the inclusive and pluralistic nature of the spiritual agencies in Igbo religion, Igbo religious 
practice includes both animal offering and gifts including speech, body movement, sacrifice and communal meal sharing. In addition, it projects important symbolism of the religion showing that rituals are covered by the premise that nature brings the child into the world but the society creates the child into a human being, a corporate person. Moreover, it depicts the ceremony as consisting of eating, drinking and merriment. This study focus on the cultural and spiritual connotation of names but the present study goes further to show the link between names and human development.

Mphande [3] researches on naming and linguistic Africanism in African American culture. The key questions that surround this study are thus, how has the African naming system been retained and modified in the African diaspora?, What are the historical and cultural traits and origins of African language practice that can be said to influence contemporary African and African American cultural identity andhow does a name contribute to discourse and interlocution in the African American societies? Using Nguni language as a case study, he affirms that in line with the morphology of names in Bantu, affix morphemes appear as either prefixes and in noun class markers or as suffixes as in verbalizes. Simultaneously, he asserts that names are either lexical or derived. Furthermore, he highlights the fact that, majority of names in Nguni are derived from the process of verbalization where a verbalize suffix is attached to the verb stem to indicate the state of the action denoted. In this guise, he mentions three most popular suffixes used in the said language such as-se, ie,-we and passive suffixes. He concludes by noting that these are elements of syncretism peculiar to both African and African American cultures. This study. This study examines the phonetic aspects of names some contexts but the present study is a blend of the syntactic and pragmatic elements of proverbial names and their role in shaping the present and the future.

\section{Theoretical Framework}

Social semiotics is a new and distinctive approach to the practice and theory of semiotics where focus has changed from the "sign" to the way people use semiotic resources both to produce communicative artifacts and events and to interpret them in the context of specific social situations and practices. Semiotic resource is the key term in social semiotics which originated from Halliday [11] who views the grammar of a language not as a code or a set of rules for producing correct sentences but as a resource for producing meanings. It is in line with this perception that Leeuwen [12] defines semiotic resources when he underscores thus:

[...] as the actions and artifacts we use to communicate, whether they are produced physiologically - with our vocal apparatus; with the muscles we use to create facial expression and gestures, etc or by means of technologies - with pen, ink, and paper; with computer hardware and software; with fabrics, scissors and sewing machines (p.3).

The above citation reveals that semiotic resources can either be concrete or abstract, verbal or non verbal provided that they can contribute in one way or the other in formulating meaning in a given context. This distinguishes semiotic resources from signs. The major difference lies in the fact that the meaning of signs are pre -given while in social semiotics the term "resource" is preferred because it avoids the impression that what a sign stands for is somehow pre-given and not affected by its use.

As regards the tenets of social semiotics, its adherents perform three major functions in communication notably, they collect, document and systematically catalogue semiotic resources including their history. They investigate how these resources are used in specific historical, cultural and institutional context. Lastly, they contribute to the discovery, development of new semiotic resources and new uses of existing resources. It is worth noting that semiotic resources are not limited to speech, writing and picture making as everything done can be in different ways thus articulating different social and cultural meanings.

In relation to semiotic innovation, social semioticians partake in the discovery and development of new semiotic resources and new ways of using existing semiotic resources. They contribute to semiotic change through the use of metaphor and connotation. The use of metaphor as a key principle of semiotic innovation originally meant "transport" where it is believed that meaning can be transported from the domain of its usual application to another domain on the basis of an imputed similarity between the two domains. Unlike metaphors that we live by, connotations are not always innovative as they often communicate well-established dominant ideas. The principle of connotation in relation to invention and innovation therefore, is based on "importation" which is an essential feature of the semiotic landscape of this era of global culture. As an example of this state of affairs, fashion designers constantly import ideas from other periods, cultures and science-fiction costumes in movies to connote the ideas and values attached to those periods thereby providing people with resources for signifying their allegiance to these ideas, values and lifestyles.

As a contribution to the discourse on social semiotics, Najafian and Dabaghi [13] highlight it as a practical approach to the study of advertising. They assert that they better communicate with customers and make the product more popular among them in order to achieve the goal of everlasting purpose and popularity. They further posit that these sets of signs do not make 
up a single, comprehensive and coherent meaning and the meaning of particular signs are in a way relative to specific kinds of reader and on specific occasions. Finally, they opine that semiotic analysis occupies an important place within a common framework of critical discourse analysis of advertising given that the attention is on signs as a carrier of ideological meanings. In this study, both the past and all the different components of Papiackum proverbial names serve as semiotic resources in generating non literal meaning and the intended illocutionary force in social interaction.

\section{Geopolitical Presentation, Social History and Occupation}

Baba I, whose language is the object of this study, is among the thirteen villages that constitute present day Ngoketunjia Division in the North West Region of the Republic of Cameroon. This village is situated at about forty kilometers from Bamenda along the ring road that leaves Bamenda to Nso. In the North, it shares a boundary with Oku which is a Sub Division in Bui Division. In the East, there is Babessi village. In the South East, it shares a short boundary with Bangolan which is among the four Fondoms that constitute Babessi Sub Division. In the South, there are Bambalang and Bamunka Fondoms which are within Ndop central sub Division. In the West, there is Babungo Fondom which constitutes one of the four Fondoms of Babessi Sub Division.

As regards their origin, these people came from Refum which was the capital of the defunct Tikari kingdom now known as Mbamkin in the Adamawa Region of Cameroon. They came from some places in North Cameroon like Maroua, Garoua and Ngaoundere. They left North Cameroon during the Jihad wars and moved to the South. It is alleged that they belong to the Takari ethnic group and arrived North Cameron from Egypt. When they got to the South of Cameroon, they created their Fondom with the urge to foster their unity. They call their village Piack translated as "migratory people" This coinage is the result of their history marked by migration before settling to their present site. Structurally, they have institutions that perform political and socio - cultural duties. Politically, Mwamgang as the highest institution in this village has the power to sanction cases of indiscipline, enthrone a new Fon (a traditional ruler) and judges issues related to murder. Besides, there is the Shag known as women's parliament whose role is visible in times of conflict or war, is an association of Baba I Moslem Women. It is a solidarity group that assists its members in difficult situations. In addition, some large families have esoteric societies which carryout death celebrations of their members.

As a manifestation of the African communal lifestyle, all the Papiackum except the minors are divided into age groups. When each group of young people who are almost of the same age reaches the age of maturity, they form their age group and contact the traditional ruler to give them a name. In case all the members of an age group die, their property is taken to the palace after the death celebration of the last person. In terms of occupations, they practice agriculture with rice farming as their principal activity. They developed a lot of interest in rice cultivation when the prices of coffee fell in the world market. The cultivation of maize, beans, cassava and other food crops is also in vogue and done mostly by women. These crops both serve as food and cash crop for the wellbeing of the population.

\section{Papiackum Proverbial Names as Discourse}

During the 1970's, language as discourse began to gain grounds partly as a response to the dominance of the Chomskyan view of language as a system that focused mainly as disconnected or decontextualised units of phonology, syntax and semantics. As a response, Halliday [11] rejects Chomskyan emphasis on grammar and highlights language as meaning potential where sets of options in meaning are available to the speaker-hearer in social contexts. He thus views language as means of functioning in society. Elce-Murcia and Olshtain [13] on their part view discourse as "an instance of spoken or written language that has describable relationships of form and meaning that relate coherently to an external communicative function or purpose and a given audience / interlocutor". Summarily, the focus here is on a connected and contextualized unit of language use. In this light, most Papiackum proverbial names are interpreted as connected speech acts based on their historical context. Below are a collection of some Papiackum proverbial names collected through interview their English versions, their historical context of production and their illocutionary point in social interaction. It is thus based on their functions that these names are classified as directives (an attempt to get the hearer to perform some future action), assertives (an attempt to represent an actual state of affairs), commissives (an attempt to commit the speaker to a future course of action), declaratives (an attempt to bring about a change in some institutional state of affairs) and expressive (an attempt to express a psychological state).

To begin with, the first name collected is termed Yewohmbeungi translated as "He who sees and likes?" In giving the circumstances surrounding this name, the bearer narrates a dreadful incident which took place in their family compound in the village some twenty years ago. As the story goes, his two elder brothers were alleged to have been killed through food poisoning by a supposed step mother. The bearer of the said name also affirms that his mother attributed such act to the fact that her two children had progressed in life especially through material wealth while the children of the co wife were living in abject poverty without any hope. The bearer of this name also opines 
that he was born five years after the above mentioned event and his mother decided to attribute to him the said name. The name is in the form of a rhetorical question which addresses the evil nature of humanity manifested through jealousy. From the history stated above, the step mother who is suppose to incarnate motherly love but is projected as a symbol of evil which characteristic of humanity. In choosing such a name, the mother of the bearer is telling him to be careful with his life as society hates those who are progressing in life. In other words, this name addresses the hypocritical nature of man who can feign happiness in the face of another person's success.

Secondly, there is the name thus, Peurimentah meaning "They have said it all". The bearer of this name affirmed that the name was given to her by her father. She further asserts that her father used to be a breadwinner in her elder sister's household providing basic necessities for her entire household. As time went on, and with a lot of responsibility, her father reduced her support to his elder sister to concentrate much resource on his own family. As if this was not enough, four of his elder sister's children fell ill and died, and it was rumoured in the village by the said elder sister that her brother is a suspect as he belonged to a secret society. From the experiences of the father of the name bearer, this name addresses the fact that no matter one's good deeds, people must always talk negatively. In other words, the name is in a form of a declarative statement where the bearer of the said name is advised to be careful in society as some people find pleasure in tarnishing people's images. In this case, society is called upon to accept talking whether positively or negatively as a natural tendency in every human community. The pronoun "they" represents those who disintegrate families the society with baseless accusations.

In addition, Shiwohndre referred to as "Who knows the world?" is a current name among the Papiackum. The person referred to in this study revealed that his grandfather gave him the said name. He went ahead to say that his grandfather is an old man in the village with twelve children and three wives. As the story proceeds, these children are all primary school dropouts and the boys have indulged in the consumption of drugs while the girls are in prostitution and cohabitation. The said grandfather sees no hope in his children as there is no one capable of taking care of him at old age. It is alleged the person providing his basic needs and taking care of him is his nephew called Shiwoh whom he had attempted to divorce his parents. As the bearer of the name notes, it is based on these events that his grandfather gave him the said name. Just like the first name, this one is in the form of a rhetorical question where the said grandfather addresses the uncertainty of the world. In doing so, he calls on the bearer of the name to be exemplary in his doings as the world is full of uncertainties. The philosophy expressed through this name can be likened to be biblical saying that the rejected stone shall become the corner stone. In other words, benevolence should not be restricted to a particular person or family. In other words, nobody knows the future.

Likewise, Tahmbominyi meaning "Leave it to God" is another name that has a spiritual undertone. In the course of our discussion with the coiner of the name, she affirmed that she also bears the name alongside her nephew. She also noted that she coined the name based on her strong Christian faith and the temptations she has gone through in her life. She thus began her story by ascertaining that in 2006, her neighbor called Nchumenu was caught by some villagers destroying crops in her farm. When she was informed, she inquired from her but she claimed to be innocent. Despite the mass destruction in her farm and frequent calls by family members to report the matter to the quarter head or avenge, she refused saying she had forgiven her. The second case was when it was alleged that her family friend called Faminyi was responsible for the protracted illness of her son. As the story goes, her son had been seriously sick of kwashiorkor for four years. During this period, her friends and family members knocked at the door of a soothsayer to know the cause of the illness. Upon returning, they accused Faminyi who had been noted for her evil deeds in and around the village. When Tahmbominyi got this information while at the hospital with her son, she cried and said God is always in control. She also extended greetings to the evil doer saying that God should grant her long life and prosperity. From these past events, one can affirm that this name highlights the view that only God has the power to judge evil doers manifested by the victim's kindness and humility in the face of trauma. The pronoun" it" represents evil deeds. The message projected by this name can be likened to the biblical message where on the last day; God will judge humanity and the righteous will be rewarded with Heaven while the unrighteous will be condemned in Hell.

Moreover, a name appeared as Fuepeundap known as" The Chief is in the house". The bearer of the said name confirmed that the name was given to him by his father after a working session with his paternal and maternal uncles. He further attested that the said name as his father confided in him was inspired by misdirected charity suffered by his family. He went on to narrate two cases where the first involved a boy called Musa whom his family provided him lodging and feeding when he was in secondary and school but upon recruitment in to the public service as a trained teacher, he is yet to manifest a sign of gratitude to the said family. The second case involved a young girl called Ajaratou who grew up with the said family and ever since she got married, she has never called or greeted anyone in the said family. Just like the second name, this name is in the form of a declarative statement 
which addresses the issue of unrecognized charity. Through this name, the family indirectly warns its bearer that no matter the good things you do to a non family member, it will not be appreciated. The chief symbolize a hero while the house symbolizes the family. In other words, it insinuates that one can only become a hero in his family if his charity is directed towards the said family. Put differently, the said name calls on its bearer not to copy the example of his family but to direct his charity to his family. This can be likened to the adage that charity begins at home although it should not end there.

Furthermore, Yoghombominyi presented as "Hear from God "was projected as a name. The bearer of the said name noted that the name was given to her by her maternal aunt called Yogyu. She affirmed that her aunt has never told her the reason behind such a name. But she asserted that she might have been inspired by her prolonged difficulties in conceiving a child. As the story goes, she affirmed that the said aunt got married at the age of twenty and could only conceive at the age of forty eight. During this period of difficulties, she experienced a lot of psychological torture from her in laws who considered her to be barren. They went further to oblige her to abandon her marriage which she vehemently refused. As if this was not enough, they told her to consult traditional doctors or adopt children whom she refused to yield to their calls but spent her time praying and fasting. From these past events surrounding the giver of the above mentioned name, it can be deduced that the name means we should wait for what God has in stock for us. The bearer of the said name is called upon to exercise patience in life if she wishes to benefit from God's plan and hence enter the kingdom of God.

Also, Pangmashi considered as «Fine in the road" was identified as a name. The bearer of this name said the name was given to him by his senior cousin named Ndashi who is based in the village. The bearer of this name noted that the cousin has suffered on two occasions from food poisoning by an uncle called Moh Suifue who always invited him in ceremonies in the village. The first case was during the Menyi festival which is characterized by eating, drinking and dancing. The cousin in question ate poisoned food and fell ill three days later. After consulting a soothsayer by some family members, it was alleged that Moh Suifue was the author of the act. The second instance was during the funeral celebration of Moh Nkong, a prominent notable in the Papiackum palace. As usual, in the course of merrymaking, the said cousin also ate poisoned food which a soothsayer later attributed it to Moh Suifue, his friend. From the experiences of the said cousin, one can say that this name addresses the issue of appearance versus reality. In other words, it point at hypocrisy which was manifested by Moh Suifue, a supposed friend. The term Moh is an honorific title accorded to notables. It is ironic that title holders who are supposed to be custodians of morality and tradition are instead those indulged in evil machinations. In this light, the bearer of the said name is called upon to be careful with those who manifest outward kindness with evil intentions. Put differently, this name also guards against hypocrisy.

Again as a popular name among females is Pangmwe which literally stands for "A person is good". The bearer of this name said that it was given to her by an old man called Salifu who is their immediate neighbor in the village. She noted that this old man was duped and he joined a secret society to acquire material wealth by sacrificing family members. In the space of seven years, he had sacrificed his wife and four children and also bought a luxurious car. These macabre deaths raised eye brows in the village as the said old man was the lone occupants of his house till his death in 2015. In respond to this incident, he was taken to the shrines of three soothsayers who all confirmed that he belonged to a secret society and that they can remove him from it. In this light, some cleansing was done on him but did not change his status as he remained lonely till death. From the experience of the said old man, one can suggest that this name highlights the view that human relationship is better than money given that he had wealth but nobody to share it with. This name calls on its bearer not to sacrifice human beings for material things. In other words, it satirizes vanity at the expense of human beings. This idea could be linked to the biblical view thus,"what shall one gain if he gains the whole world and loses his soul?"

In a similar vein, we met a young man whose name is Ngangchi meaning "a powerful country". Prior to giving the details surrounding this name, he noted that the first name given to him by his father was Mwembengheri translated as "A person who hates himself". He declared that he changed this name because there is a general feeling among the Papiackum that if one bears a certain proverbial name like his former name, it will affect his or her life if it symbolizes a negative ideology or attribute. Having said this, he affirmed that his new name as mentioned above was coined by him and established a new birth certificate. He further noted that he was inspired by the realization of many developmental projects in Baba I by the Fon and the elites. He cited projects such as the construction of the palace which stands as the best among the thirteen villages that constitute the Ndop Fondom, the supply of pipe borne water and electricity. From these facts, one can say that its bearer is insinuating that the growth of any village or nation depends on the contribution of its citizens. The word "powerful" represents development. In other words, development depends much on the hard work of a population. This calls on the bearer of this name to be a major actor in the development of his village and by implication the nation. This is in line with the popular 
views that ask not what your nation has done for you but what you have done for your nation.

As we proceeded with the name search, we stumbled on a middle aged man called Fahndi which means "To give and sleep". In the course of our discussion with him, he noted that he was told that the name giver was his deceased great grandfather called Yarshike who had done a lot of sacrifice both at the family and at the community levels. Firstly, he was constantly at logger head with the Fon over his pieces of land .He had been summoned three times by the Fonasking him to offer his two pieces of land for the construction of government schools or stand the risk of being exiled from the village. Being too worried about his imminent exile, he offered and is presently hosting a government primary and secondary school. Secondly, he declared that his great grandfather who had a lot of wealth was constantly being pressurized by his mother to offer material and financial help to the poor in the family. In response, he provided financial assistance to most of his family members pursuing education and capital to those indulged in business. All these actions made his late mother to be very happy with him and while on her sick bed shortly before her death, poured blessings on him and express the wish that such gestures should continue even in her absence. From this background information, it can be deduced that the word "give" represents sacrifice while "sleep" stands for peace. This name thus evokes the idea of sacrifice in achieving peace. In other words, the giver of the name is insinuating that internal peace should not be jeopardized by the insatiable quest for material possessions. He therefore acknowledges this idea by sacrificing some of his land and money for the wellbeing of the community. This calls on the bearer of the name to do same to achieve psychological tranquility.

As regards names related to God, we also had Ndrembominyi meaning "The world is in the hands of God". The bearer of this name made us to understand that the name was coined by his maternal grandmother as a result of a series of misjudgments by his family and the village as a whole. Firstly, he mentioned the fact that the entire village had stigmatized his family as a family of death. This is because his mother loss six children within a period of two years. This stigma therefore made this family to be looked upon negatively given that nobody created friendship with them, no one came for marriage and they lived in total isolation. At the family level, his mother cried and screamed saying that wizards and witches have decided to render her childless as she knew that the five children left are bound to die. As time went on, no death was recorded in this family to the surprise of its members and the entire community. Later on, other families who had jubilated over this misfortune became victims. He cited the case of Mbongke family who loss nine children in the space of one year.As a result of this situation, these families became families of death while that of Ndrembominyiwas termed Wutirma meaning death has refused me. Drawing inspiration from this background knowledge, one can affirm that this name projects the idea that God is in control of this universe and no one can determine his or her destiny. Put differently, it underscores the fact that the power of judgment is in the hands of God and not man depicted in this story by the transfer of misfortune from one family to another. This therefore cautions the bearer of this name not to render judgment to any human action as no one knows his fate in advance.

Still in relation to the uncertainty surrounding life, we came across a lady whose name we had as Njinguela meaning "No matter what I do". In the course of our discussion with the bearer of the name, she said that the name was coined by her step mother called Nkipang meaning "a good basket" who had suffered from series of disappointments in her life. She started by making allusion to her marital life characterized by regrets. She cited the first case when she was fianced to a gentleman called Nchiminyi whom despite her faithfulness, abandoned her when he picked up a job as a prison superintendent in Buea.The second case was when she got married to a notable called Moh Isofa. After having a child with him and coupled with her loyalty, he abandoned her for another woman. The third case was her neighbor and friend who moved around in the village spreading false information about her. As the story goes, this neighbor in question called Mbeme lived with her for five years when her house when her house got burnt. Despite her humanism towards her, she went around proclaiming that she is a witch and has attempted killing her on several occasions. This name under study is presented literally with the use of suspense. From the background information of the name presented above, the can be reshaped thus "No matter what I do, I meet only misfortune». This highlights the significant role of past events providing to names. This name expounds on the evil nature of humanity who reciprocates righteousness and kindness with hatred like the case of Nkipang.This name cautions its bearer to be careful as human beings are innately evil in nature.

To further depict the inherent evil in man, there is the name titled Pangsui meaning "A friend is good". The bearer of this name affirmed that the name was coined by his cousin who also bears the same name. He noted that his cousin confided in him that this name was given taking in to consideration a series of problems that he had with his brothers and sisters. He began by evoking the disagreement in his family as a result of successorship.As the story goes Pangsui is the successor of his father called Shifue who died twenty years ago. As tradition demands, he is supposed to be the caretaker of family property while ensuring that his immediate family members benefit from it. Few years later after the death of his father, disagreement 
arose.Firstly, his elder sister became too arrogant towards him and seized the land certificate of all the landed property.Secondly, one of his younger brothers who is a medical doctor in Britain, came back to Cameroon only to accuse him of embezzling family funds to the tune of eleven million francs. As if this was not enough, another younger brother contacted a sorcerer and proposed him some money to kill the successor. From these evil deeds perpetuated in the story above, one canascertain that this name is borne out of family disunity. Put differently, this name underscores the view that a good friend is preferable in the context where family members are bad. This name satirizes this society whereby the family is no longer considered as the basic unit of society. This is justified by the fact that the image of a family is that of care and love but the one presented here is characterized by hatred. This name therefore, is related to the adage that a good friend is better than a bad brother.This calls on the bearer of the name to be very careful when interacting with evil intentioned family members.

Still in relation to the evil nature of man, the Baba 1 community has nicknamed a soothsayer as Mashi Moh Fendi "the wrong road". We got interested in this case because his real name is Boblebut the name that is increasingly gaining grounds is the one mentioned above. When we spoke with two old men named Njengang and Mafue Shangha, they began by narrating the origin of the name and the circumstances that led to its attribution to its present bearer. They asserted that Moh Fendi is a legend who lived as a well respected prince. It is alleged that he misled the Papiackum as they embarked on migration in search of a suitable area to settle. In this connection, when they left Menyog, Moh Fendi went and stood on the right path and directed the person to a swampy area. The result was that many people sank. The situation was stopped only when somebody followed another one closely and saw him or her sinking. From this story, they affirmed that if one says that he has been showed the path of Moh Fendi, it means that he has been deliberately misdirected. They further ascertained that this name has been attributed to this soothsayer because he has used and is still using his doubtful prophetic powers to extort money and creating hatred in some families. As if this is not enough, he jeopardizes the lives of young girls by assisting them to carry out abortion. Drawing inspiration from these events, one can insinuate that Moh Fendijust like the soothsayer symbolizes deceit. It is also ironical that Moh Fendi who was a highly respected notable was the one who misdirected his people in to a swampy area as they migrated from one place to another. This puts to question the role of notables in society. This calls on the entire Papiackum not to follow the footsteps of this notable and to watch out against the deceitful nature of the soothsayer. Put differently, this name projects the view that soothsaying is associated with lies telling and illusion.
Finally, there isChoteunju translated as"Arranges it and eat" as a common name among the Papiackum community. The bearer of the name affirmed that the said name was given to him by an uncle who also bears the name. This uncle as he disclosed to us has registered much successes from his investments in the past years. The first case is his first son called Pangmashi who is a civil administrator working at the governor's office in the South region of Cameroon. The second is a daughter called Yogyu who graduated from the Faculty of medicine and Biological Science and presently working at the Douala general hospital. He also has a son called Sobse has Doctorate degree in Law. All these successes have made the said uncle a happy person as he lives in a well furnished house and drives in a luxurious car. From the life of the uncle, one can affirm that the name highlights the view that hard work accompanies success. The use of the word "arranges" represents hard work or investment while "eat" represents the proceeds from hard work. This name projects the idea of filial love that has been reciprocated through a show of gratefulness manifested by the children. This name can be likened to the adage that as you make your bed, so shall you lie on it. It therefore satirizes those who want to reap when they did not sow. This name instructs its bearer to work very hard if he hopes to have a bright future and that of his children and by implication society at large.

\section{CONCLUSION}

In conclusion, this study has attempted to cast a look at the inseparable link between Papiackum proverbial names and past events. The study has also noted that proverbial names serve both as proverbs as well as names. The link between these proverbial names and history on the one hand and their meanings in daily social interaction constitute the crux of this paper. Furthermore, we found that, in the said community, the people are very inventive in coining proverbial names where some appear as declarative statements and others as rhetorical questions interpreted as connected speech acts embedded in symbolic representations. Also, in as much as these proverbial names are being coined on a daily basis, some have existed for decades and constitute part of their oral tradition hence their cultural identity. From the prism of social semiotics, this study affirms that proverbial names are speech acts whose meaning in social interaction depends much on some historical facts of the coiner of the name or the family as a whole. Secondly, proverbial names when interpreted highlight certain values ranging from philosophy of life, cultural taboos, and values to norms. Thirdly, these names when interpreted can be grouped in line with the taxonomy of indirect speech acts proposed by Searle [14] as directives (Shiwohndre, Tahmbominyi, Fuepeundap, Ndrembominyi, and Choteunju), assertive (Pangmashi, Pangmwe, and Pangsui), commissives (Ngangchi and Fahndi)declaratives (Njinguela and Mashi Moh Fendi), expressive (Yewohmbeungi, Peurimentah and 
Yoghombominyi) Finally, in as much as proverbial names are linked to the past, they reinforce as well as put to question certain past and present values. In this light, it also calls on the bearers of proverbial names to either effect changes or adopts certain ideological orientations for a better communal life.

\section{REFERENCES}

1. Blumer, H. (1986). Symbolic Interactionism: Perspectives and Method. Berkeley and Los Angeles, California: University of California Press.

2. Nwoye, A.M.C. (2014). An ethnographic Study of Igbo Naming Ceremony. International Journal of Sociology and Anthropology, 6(10), 276-295.

3. Mphande, L. (2006). Naming and Linguistic Africanism in African American Culture. Selected Proceedings of the $35^{\text {th }}$ Annual Conference on African Linguistics, 104-113.

4. Brewer, F.W. (2005). What is Recollective Memory? In D.C. Rubin (Ed), Rememberingour Past: Studies in Autobiographical Memory (pp.1965).Cambridge, UK: Cambridge University Press.

5. Bergson, H. (1988). Matter and Memory. 1896. Trans. Nancy Margaret Paul and W. Scott Palmer. London, G. Allen \& Co., ltd.
6. Russell, B. (1921). The practice and theory of Bolshevism. G. Allen \& Unwin Limited.

7. Malcolm, N. (1963). Knowledge and certainty: Essays and lectures.

8. Rubin, D. C., \& Kozin, M. (1984). Vivid memories. Cognition, 16(1), 81-95.

9. Anderson, M.J. (2007).The Grammar of Names. Great Clarendon Street, Oxford: Oxford University Press.

10. Ogunwale, A.J. (2012). A Pragmalinguistic Study of Yoruba Personal Names. Journal of Literary Onomastics, 2(1), 24-34.

11. Halliday, M. A. K. (1978). Language as social semiotic: The social interpretation of language and meaning. Hodder Arnold.

12. Leeuwan, V.T. (2005). Introducing Social Semiotics. New York: Taylor and Francis Group.

13. Najafian, M., \& Dabaghi, A. (2002). Hidden Language of Advertising: A Semiotic Approach. Proceedings of the International Conference: Doing Research in Applied Linguistics, 20-24.

14. Searle, J.R. (1979). Expression and Meaning. Cambridge, UK: Cambridge University Press. 